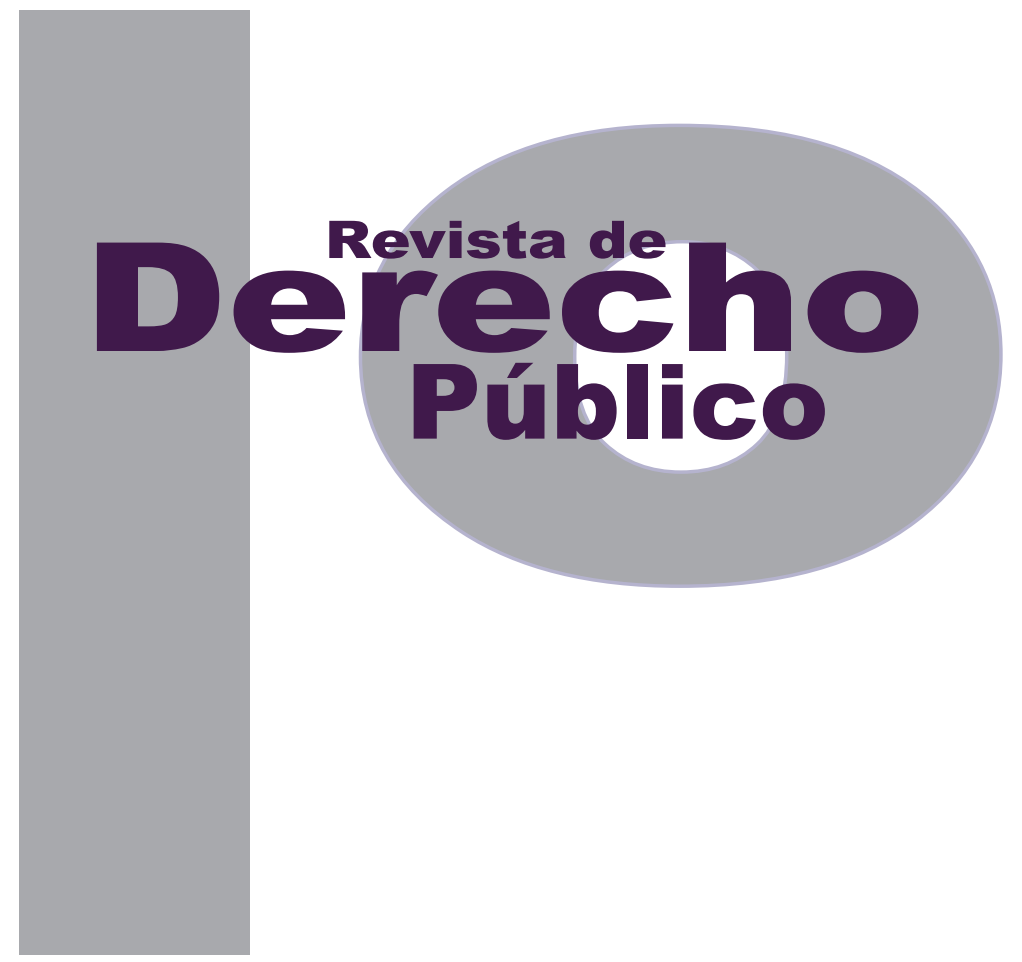

\title{
UNA CASA DE VARIOS PISOS: ACCESO A LA JUSTICIA EN CASOS DE VIOLENCIA INTRAFAMILIAR EN UNA COMISARÍA DE FAMILIA DE BOGOTÁ
}

\author{
Alejandro CÁCERES MONROY
}

Universidad de los Andes

Facultad de Derecho

Revista de Derecho Público N. ${ }^{\circ} 28$

Enero - Junio de 2012. ISSN 1909-7778 


\title{
Una casa de varios pisos: acceso a la justicia en casos de violencia intrafamiliar en una comisaría de familia de Bogotá
}

\author{
Alejandro Cáceres Monroy ${ }^{1}$
}

\section{RESUMEN}

Este artículo visibiliza algunas de las formas en que las autoridades jurídico-administrativas atienden casos de violencia intrafamiliar en Bogotá. Se destacan las siguientes conclusiones: 1) El análisis de los campos de administración de la violencia privada rompe esta desconexión aparente y muestra que la fuerza ejercida en contra de las mujeres dentro de los hogares puede ser leída como una consecuencia de las fallas del Estado en el monopolio de la fuerza. 2) La administración pública de la violencia doméstica muestra al tiempo informalidad e instrumentalidad, pues: i) desarrolla cadenas de funcionamiento basadas en procedimientos y competencias no previstos formalmente; ii) articula definiciones particulares del fenómeno de la violencia intrafamiliar, sobrestimando el valor del conflicto como corresponsabilidad y opacando la violencia psicológica frente a la

\section{ABSTRACT}

This article shows some findings on the way judicial and administrative authorities handle domestic violence in Colombia. The following conclusions are worth of mention: 1) The analysis of domestic violence's administration scenarios breaks this apparent disconnection and shows that the violence against women in their homes can be read as a consequence of the failure of the State to uphold the means of violence. 2) Public administration of domestic violence shows both informality and instrumentality because: i) it develops chains of behavior based on procedures and faculties not provided for originally; ii) it articulates particular definitions of domestic violence, overestimating the importance of conflict as co-responsibility and underrating psychological violence as opposed to physical violence as the archetype of "violence in the family"; iii) it renders the prediction of the possible

1 Estudiante de último semestre de Derecho y Ciencia Política, Universidad de los Andes. Grupo de investigación en Derecho y Género (IDEGE). Miembro del Programa de Acción por la Inclusión y la Igualdad Social (PAIIS). Correo electrónico: ca.caceres950@uniandes.edu.co 
agresión física como arquetipo de "violencia en la familia"; iii) hace imposible la predicción del comportamiento de los funcionarios encargados de determinar los derechos involucrados. 3. La investigación muestra que la regulación de la violencia intrafamiliar ha creado sistemas de incentivos que contradicen el objetivo inicial de la protección de los derechos de las mujeres.

Palabras clave: Violencia. Decisiones administrativo-judiciales. Comisarios de familia. Violencia intrafamiliar. Medidas de protección. outcomes of the procedures impossible. 3. The research shows that the regulation of domestic violence has created a system of incentives that contradict the original aim of protecting women's rights.

KeY words: Violence. Administrative-judicial decisions. Colombian officials on family issues. Domestic violence. Protection orders. 


\section{SUMARIO}

Introducción - I. VIOLENCIA INTRAFAMILIAR Y COMISARÍAS DE FAMILIA EN BOGOTÁ - A. Universo y muestra - B. Las Comisarías de Familia, una revolución en los conflictos familiares - II. HERRAMIENTA METODOLÓGICA - A. Las entrevistas - B. El trabajo de campo - C. Límites y claves de interpretación - III. EL SISTEMA DE PROTECCIÓN FAMILIAR Y LAS BARRERAS DE ACCESO - A. Vengo para una denuncia de violencia - B. La violencia es... - C. Lo que importa son los hechos - D. La perversión de las medidas de protección - E. Un trabajo interinstitucional - F. Eso no es violencia, es conflicto - G. Para un conflicto se necesitan dos. - IV. CONCLUSIONES - Bibliografía. 


\section{Introducción}

Colombia ha sido clasificada como uno de los países más violentos del mundo ${ }^{2}$, hecho que representa, en algún sentido, la forma en que la violencia se ha convertido en parte de la historia política y social del país ${ }^{3}$. La violencia que se suele reconocer en Colombia ha sido la de carácter público, la violencia de los actores armados, la de los movimientos sociales, la de los partidos políticos en crisis, y hasta la de las calles en las grandes ciudades.

Sin embargo, al desplazarse de lo público a lo privado, si bien el nivel de violencia no se modifica ${ }^{4}$, el interés y la producción académica sí lo hacen ${ }^{5}$. De ahí, que son pocos los autores que relacionan de manera directa la forma en la que se ejerce violencia pública y en la que se ejerce violencia privada; "Ios actores armados en casa,

2 Según el ranking del Global Peace Index, para el 2009 y el 2010 Colombia ocupaba el lugar 138 de 149 países en el mundo. Tomado de www.visionofhumanity.org, consultado por última vez el 20 de agosto de 2010 a las $13: 47$

3 De esto podrían dar cuenta la gran cantidad de producciones académicas y de académicos que se han dedicado a hablar de la violencia política y los problemas sociales y económicos que esa violencia acarrea. Ver por ejemplo, Bolivar (2006), Camacho $(2003,2006)$, Duncan (2006), Guillén (1996), Leal (2002), Romero (2003, 2005, 2006), Palacios (2005), entre otros.

4 De acuerdo con la Encuesta Nacional de Demografía y Salud (ENDS), dos de cada tres mujeres consultadas contestaron que sus esposos o compañeros ejercían o habían ejercido situaciones de control contra ellas. Las situaciones más frecuentemente mencionadas fueron: el esposo insiste siempre en saber en dónde está ella (37 por ciento), el esposo la ignora (36 por ciento), el esposo le impide el contacto con amigos o amigas (26 por ciento), y el esposo la acusa de infidelidad (26 por ciento). Tomado de www.profamilia.org, consultado por última vez el 24 de mayo de 2009 a las 20:36.

5 Aunque hay bastante producción académica respecto a la violencia intrafamiliar, en la gran cantidad de escritos sobre el tema no es fácil encontrar una relación clara entre la violencia política en Colombia y la violencia doméstica. Ver Relatoría en Violencia Intrafamiliar, Universidad de los Andes http://relatorestematicos.uniandes.edu.co/ index.php/es/violencia-intrafamiliar.html han sido por lo regular desconocidos en lo que se ha denominado estudios sobre la violencia" (Pineda, 2004: p. 2), de esta manera, se hace necesario reconocer que si bien la violencia doméstica no tiene una relación obvia con la pública, la primera "sí puede ayudar a construir una cultura de la violencia convirtiéndose en un caldo de cultivo para la pública" (Castellanos, et al. 2001 p: 172) y por qué no de manera inversa.

La violencia intrafamiliar ha sido reconocida como una forma especialmente insidiosa de ejercer el control sobre miembros de la familia y de practicar violencia privada. En Colombia es un problema relevante y reiterado; las cifras de la Encuesta Nacional de Demografía y Salud ${ }^{6}$ (ENDS) y la cantidad de casos que reciben las Comisarías de Familia en Bogotá por problemas de violencia intrafamiliar, dan cuenta de ello? De la misma forma, la respuesta normativa al tema tampoco ha sido poca: el artículo 42 de la Constitución Política de 1991, la ley 294 de 1996, la ley 575 del 2000, el decreto 652 de 2001 y la ley 1257 de 2008 se han producido en respuesta a la violencia intrafamiliar; en igual sentido, una cantidad considerable de sentencias de la Corte Constitucional $^{8}$, y

6 Para el año 2008 sólo las Comisarías de Familia de Bogotá recibieron 143.240 solicitudes de servicio por casos de violencia intrafamiliar. Tomado de: Secretaría de Integración Social de Bogotá, Sistema de información y registro de beneficiarios -Sirbe-. Información actualizada a 6 de enero de 2009, a la que se accede como fruto de un derecho de petición que el autor de este artículo presentó el 6 de marzo del 2009 ante la Secretaría de Integración Social (Ver anexo a).

7 A pesar de que no se presentan otras cifras, como las de las fiscalías, estaciones e inspecciones de policía, centros de salud, entre otros que también son receptores de casos de violencia intrafamiliar que no siempre se transforman en denuncias, por lo que sería lógico pensar que la proporción del problema es mucho mayor.

8 Al respecto las sentencias: T-416/2006 M.P. Rodrigo Escobar; T-282/2002 M.P. Manuel Cepeda; T-297/1999 M.P. Carlos Gaviria; 
adicionalmente instrumentos internacionales vinculantes ${ }^{9}$ así como decisiones, recomendaciones y sentencias ${ }^{10}$ dan fe del interés y desarrollo que el tema ha tenido en la región y en el ámbito internacional.

Así, se puede decir que el tema de violencia intrafamiliar ha sido tratado por el Estado colombiano y se ha visibilizado como un proble$\mathrm{ma}^{11}$ en el cual este tiene un papel principal en la sanción y erradicación. Respecto de este papel, los académicos se han pronunciado y han criticado aspectos de la normativa, tales como la conciliación (Pineda, 2003; Lemaitre, 2002; Galvis, 2001), las medidas de protección (Pineda, 2004; Lemaitre, 2003), entre otros. Estos trabajos se abordaron metodológicamente desde el estudio de expedientes (Lemaitre, 2003), charlas con los usuarios (Veeduría Distrital, 2009; Pineda, 2004; Lemaitre 2002 y 2003), conferencias grupales con comisarios de familia (Pineda, 2004; Lemaitre 2002 y 2003), entre otros. De esta forma, se descubrió que el acercamiento personal con los comisarios y las comisarias de familia no había sido sistemático y se tenían conclusiones a partir del estudio de

T-460/1997 M.P. Antonio Barrera; T-391/1995 Fabio Morón, entre otras.

9 Convención Belem do Pará en el marco de la Organización de Estados Americanos, Convención sobre la Eliminación de todas las Formas de Discriminación Contra la Mujer (CEDAW) en el marco de Naciones Unidas y su Protocolo Facultativo.

10 La decisión de la Comisión Interamericana de Derechos Humanos: Informe No 54/01. Caso 12.051. Maria da Penha Maia Fernandes contra Brasil y el Caso No. 12.626 González contra Estados Unidos, las recomendaciones del Comité para la Eliminación de la Violencia contra la Mujer, comité que controla la CEDAW, entre otros.

11 Según el Decreto 3039 de 2007 por el cual se adopta el Plan Nacional de Salud Pública 2007-2010 la violencia intrafamiliar es un problema de salud pública en el que el Estado tiene que intervenir desde su etapa preventiva. lo que decían los usuarios o los expedientes, y lo que algunos comisarios no diferenciados por localidades, géneros y experiencias habían dicho en conferencias o capacitaciones.

Por ello, el propósito de este trabajo es aproximarse a la forma en que los comisarios y comisarias de familia de una Comisaría de Familia de Bogotá, usan las herramientas legales en casos de violencia intrafamiliar ${ }^{12}$, para evidenciar qué los motiva a decidir de una u otra manera, cuáles son los retos a que se enfrentan las víctimas y, finalmente, qué ocurre en cada etapa del proceso de atención en los casos de violencia intrafamiliar.

\section{VIOLENCIA INTRAFAMILIAR Y COMISARÍAS DE FAMILIA EN BOGOTÁ}

La pregunta que guía este trabajo parte de la necesidad de entender cómo son aplicadas las leyes sobre violencia intrafamiliar por los comisarios de familia, en una localidad de Bogotá, desde el momento de la denuncia hasta la decisión final.

\section{Universo y muestra}

En Bogotá existen veinte localidades: Antonio Nariño, Barrios Unidos, Bosa, Candelaria, Chapinero, Ciudad Bolívar, Engativá, Fontibón, Kennedy, Los Mártires, Puente Aranda, Rafael

12 Es importante hacer notar cómo los mismos comisarios aseguran que cada localidad es muy distinta y cómo se tienen que aproximar según las necesidades de cada localidad en la que se encuentren y no de los supuestos que traían de otras. Sin embargo, en una investigación sobre la propiedad informal y la violencia intrafamiliar realizada por Julieta Lemaitre, próxima a publicarse, muchas de las dinámicas de las Casas de Justicia y de las Comisarías de Familia son muy similares. 
Uribe Uribe, San Cristóbal, Santafé, Suba, Sumapaz, Teusaquillo, Tunjuelito, Usaquén y Usme. Cada una tiene su propia Comisaría de Familia, lo cual significa que en Bogotá todos los casos de violencia intrafamiliar son llevados por comisarios y no por jueces promiscuos o jueces municipales, como sí ocurre en otros municipios de Colombia.

Dado el nivel demográfico de cada localidad o la demanda de servicios, hay más de una Comisaría en algunas localidades: dos en Bosa, Ciudad Bolívar, Engativá, Kennedy, San Cristóbal; tres en Suba y dos Comisarías móviles que circulan por toda la ciudad.

Como se pudo observar, Suba es la localidad que más Comisarías tiene, esto se debe a que es la localidad más grande de todo Bogotá, "para el 2009 contaba con 780.267 habitantes aproximadamente, que representan el 11,21\% del total de población de la ciudad"13. En ella "predomina el estrato 2 y el 3 con un 34.0\% y $35.19 \%$ de la población respectivamente, los principales problemas de esta localidad son la marginalización, la violencia intrafamiliar, el crimen menor (...)"14. De igual forma, Suba representa el $11 \%$ del número de órdenes administrativas de solicitud del servicio de atención en

13 Alcaldía Mayor de Bogotá, Instituto Distrital de Cultura y Turismo. Bogotá, panorama turístico de 12 localidades. Alcaldía Mayor de Bogotá, 2004 y http://www.gobiernobogota.gov.co/content/ view/121/338/ Secretaría de Gobierno de Bogotá. Consultado por última vez el 20 de agosto de 2010 a las 17:35.

Tomado de www.angelcustodiocabrera.com, representante a la Cámara por la circunscripción de Bogotá. Consultado por última vez el 25 de mayo a las 0:45. las Comisarías ${ }^{15}$, y el $13 \%$ de demandas de violencia intrafamiliar atendidas ${ }^{16}$ : Ios datos más altos de toda Bogotá. Por estas razones, se decidió trabajar con esta localidad, específicamente con la Comisaría número 1 de Suba, que es la que tiene más territorio a cargo y, además, es la única en la localidad con más de un comisario ${ }^{17}$.

\section{Las Comisarías de Familia, una} revolución en los conflictos familiares

A las Comisarías de Familia se les otorgaron funciones jurisdiccionales en la ley 575 del 2000, con el objetivo de descongestionar a los juzgados de familia y promiscuos municipales. Esto trasladó una gran cantidad de usuarios a estas entidades, así, la demanda represada de delitos y conflictos familiares ha tenido expresión en la actual congestión de las Comisarías (Pineda, 2004, p. 11).

Los comisarios hacen parte del Sistema Nacional de Bienestar Familiar y según la ley 1098 de 2006 son autoridades administrativas, sin embargo, también les otorga facultades judiciales frente a situaciones de desacato en audiencia, incumplimiento de medidas de protección, imposición de multas convertibles en arresto y facultades policivas al ordenar la

15 Secretaría de Integración Social de Bogotá, Sistema de información y registro de beneficiarios -Sirbe-. Información actualizada a 6 de enero de 2009.

16 Ibídem.

17 Lo anterior influyó mucho en la decisión de elegir a Suba como la localidad objeto de estudio y específicamente a la Comisaría 1, pues queríamos entrevistar un comisario y una comisaria y esto sólo sucede allí, en las demás sólo hay comisarias. 
retención del agresor hasta por 36 horas, por ejemplo ${ }^{18}$ (Palacio, 2008: p. 170).

\section{HERRAMIENTA METODOLÓGICA}

Para el efectivo acercamiento a la aplicación de las leyes sobre violencia intrafamiliar, se utilizó como principal herramienta metodológica la realización de entrevistas personales con cada uno de los comisarios. Simultáneamente se realizó un trabajo de campo en la Comisaría de Familia que funciona en la Casa de Justicia de Suba ${ }^{19}$.

\section{Las entrevistas}

Las entrevistas se basaron en un cuestionario de cuarenta y cuatro preguntas, dividido en tres secciones: en la primera, sobre los usuarios, se pregunta al comisario o comisaria cómo son los usuarios, qué piensan de ellos, y cómo frente a un tipo de usuario deciden de una forma determinada; la segunda, sobre las medidas de protección, indaga cuándo las decretan, con qué hechos, y su percepción sobre tales medidas se diseñó con el propósito de evidenciar si existía alguna preferencia por la utilización de una $\mathrm{u}$ otra medida de las que contempla la ley ${ }^{20}-$;

18 Según la ley 1098 de 2006 la regulación y las líneas técnicas deben ser dictadas por el Instituto Colombiano de Bienestar Familiar, como entidad coordinadora del Sistema Nacional de Bienestar Familiar.

19 Las Casas de Justicia son una iniciativa del Ministerio de Justicia y del Derecho, apoyada por la Agencia de Cooperación de Estados Unidos USAID, con el propósito de facilitar y acercar la justicia a las comunidades marginadas y excluidas. En ellas se encuentran todos los servicios legales posibles de una manera centralizada, hay oficinas de la Defensoría de Pueblo; de la Fiscalía Seccional; de Medicina Legal; atención psicológica y de trabajadores sociales; Comisaría de Familia y Consultorios Jurídicos gratuitos para personas de escasos recursos.

Aunque las medidas de protección las introduce la ley 294 de 1996 utilizamos la ley 1257 pues es la que hace las últimas modificaciones e inclusiones. la tercera, sobre los comisarios, averigua sobre su oficio como funcionarios públicos a partir de preguntas personales que dan cuenta de su relación con las medidas de protección, con los usuarios y con los procedimientos, con el propósito de controlar algunas de las respuestas antes obtenidas.

Fueron realizadas a dos funcionarios que llamaremos la comisaria $\mathrm{G}$ y el comisario $\mathrm{M}^{21}$, en la oficina del comisario ${ }^{22}$, y duraron en promedio una hora y media. Se encuentran transcritas en su totalidad y para el tratamiento efectivo como herramienta de investigación se codificaron respetando las tres secciones del formulario. Cada uno de esos grupos está subdividido en algunos códigos específicos, que apuntan a extraer información sistemática de acuerdo con los objetivos del trabajo. Así, en el nivel de usuarios, encontramos los códigos: características generales, características socioeconómicas, usuario violentado; en el nivel medidas de protección, los códigos: tipos de medidas, curso de acción, desalojo, caución; en el nivel de comisarios, los códigos: relación comisario-usuarios, relación comisario-otras autoridades (ver Anexo 1: Códigos y cuestionarios).

Estas herramientas fueron las únicas posibles, luego de fallidos intentos por acceder a los expedientes de procesos de violencia intrafamiliar

21 Los nombres se omiten por petición de los mismos.

22 El horario de atención de la Casa de Justicia, donde funciona la Comisaría, es de 7 de la mañana a 11 de la noche. Por esta razón hay dos turnos: uno de 7 a.m. a 3 p.m. y otro de 3 a 11 p.m., los cuales se rotan semanalmente. Cada comisario tiene su propio personal: asistentes de conciliación y administrativos, psicólogos, recepcionistas, equipo de medicina legal, entre otros. La oficina del comisario es la misma para los dos turnos. 
que reposan en la Secretaría de Integración Social de Bogotá, entidad que además de exigir varios requisitos argumentó una reserva legal que nunca se encontró en la ley ${ }^{23}$. A pesar de lo que dice la ley 1275 del 2008 y de la constancia de que no se usarían datos de las personas involucradas no fue posible consultar los expedientes.

\section{El trabajo de campo}

El trabajo de campo se realizó en cinco visitas a la Comisaría, de aproximadamente tres horas diarias, para observar los procedimientos.

\section{Límites y claves de interpretación}

En la conversación directa con los comisarios se logró percibir qué piensan, por qué lo hacen de tal o cual manera, cuáles son sus sesgos y cómo estos afectan su decisión. En el curso de las entrevistas se construyó un diario de campo, pues la espera para la atención por parte de los funcionarios permitía conocer las vivencias propias de la Comisaría, los funcionarios intermedios, sus interpretaciones de la ley, entre otras. Estas experiencias se transformaron en datos relevantes de investigación, que se conectaban de una manera importante con lo que los comisarios decían en las entrevistas.

Por esta razón, los resultados presentados son una aproximación a esas formas de

23 Sólo la ley 1257 del 2008, Art. 8, Lit. f, habla del derecho que tiene la víctima de violencia a ser tratada con reserva de identidad al recibir la asistencia médica, legal o social, respecto de sus datos personales, los de sus descendientes o los de cualquiera otra persona que esté bajo su guarda o custodia. interpretación legal, que deben ser combinadas con investigaciones futuras en las que se pueda acceder a expedientes y a entrevistas con el personal administrativo y usuarios de los servicios de la Comisaría, y de otras entidades que colaboran con la atención de la violencia y la protección de las víctimas, tales como fiscalías, centros de salud, inspecciones y estaciones de Policía, Iglesias, personerías, consultorios jurídicos, entre otros, pues si bien muchas de esas instituciones no tienen potestad ni función para atender casos de violencia, las víctimas con frecuencia se dirigen a ellas, lo cual las convierte en filtros anteriores a las Comisarías de Familia.

\section{EL SISTEMA DE PROTECCIÓN FAMILIAR Y LAS BARRERAS DE ACCESO}

Para entender el procedimiento para la atención de víctimas de violencia intrafamiliar, las facultades que la ley otorga a los comisarios, y más específicamente, cómo se decreta una medida de protección para las víctimas, esta sección se divide en tres partes: primera, cómo se activa el sistema para poder acceder a los comisarios; segunda, qué motiva a los comisarios para decidir de determinada forma un caso; y finalmente, un recuento de las experiencias de los comisarios frente a la utilización de las medidas de protección.

\section{Vengo para una denuncia de violencia}

Estas palabras se escuchan de manera reiterada en las Casas de Justicia de las localidades de Bogotá pues allí funcionan las Comisarías de 
Familia. En el caso de la Comisaría seleccionada para la investigación, llegar hasta el piso donde están las oficinas exige a las víctimas-usuarios no solo esfuerzo físico sino superar una serie de barreras.

A la entrada de la Casa de Justicia se encuentran los primeros dos obstáculos que hay que sortear: el primero, un aviso (Anexo 2) donde se informa al usuario que sólo debe venir si necesita atención; que si tienen niños pequeños que no son requeridos para alguna diligencia, es mejor dejarlos en casa; y que no hay servicio de baños públicos; el segundo, un vigilante que exige la presentación de una boleta para poder dirigirse al funcionario respectivo, quien no la tiene debe ir a las oficinas del Centro de Recepción de Información -CRI-, donde jóvenes de Misión Bogotá ${ }^{24}$ le preguntan por qué viene, qué necesita, qué espera que se haga y, dependiendo del caso, le informan a dónde se debe dirigir: a la Comisaría de Familia, a la Personería o al Consultorio Jurídico (todas quedan en el tercer piso) y le dan la boleta.

Ya con la boleta, después de una requisa, el vigilante le permite seguir al tercer piso. Una vez ubicada la víctima-usuario en las oficinas de la Comisaría de Familia, debe esperar a que la auxiliar administrativa ${ }^{25}$ la atienda. Sólo hay una auxiliar por turno y deben recibir a todos los que

24 Este es un proyecto de la Alcaldía Mayor de Bogotá (2007-2011) encaminado a combatir el desempleo en la ciudad a través de la figura de los "guías ciudadanos". Tomado de www.culturarecreacionydeporte. gov.co/portal/node/1713 consultado por última 22/08/2010 a las 22:16 Ninguna de las personas de Misión Bogotá tiene formación legal, psicológica o estudios superiores.

Estas auxiliares tienen formación técnica, como secretariados, asistencia administrativa, entre otras. llegan remitidos por el CRI, preguntarles qué les pasó, en dónde, quién lo hizo y con qué, y si están golpeados ver la parte afectada. Si a la auxiliar le parece que es un caso que amerita intervención le pide solicitar a la recepcionista el Registro Único de Gestión -RUG- (Anexo 3) y consignar en él los datos personales, los datos del agresor y una descripción de los hechos que motivan la consulta (tercera barrera).

Una vez diligenciado el RUG, la auxiliar lee lo que pasó y orienta a la víctima- usuario de manera sencilla, como por ejemplo: qué es lo que debe hacer y si debe volver o no a su lugar de domicilio dependiendo de dónde se encuentre el agresor. También ofrece sugerencias extra legales: les aconseja sobre su situación, les da “ayuda para sentirse mejor" ${ }^{26}$, y les insta a que denuncien los hechos de lesiones personales, amenazas contra su vida o la de sus familiares ante la Fiscalía ${ }^{27}$.

Si la auxiliar considera que el caso es de violencia intrafamiliar, aconseja tramitarlo como tal según la Ley 575; si no lo cree así, sugiere que se tramite como conflicto familiar según el Código de Policía, es decir, como una contravención (cuarta barrera). La misma auxiliar informa su decisión al comisario, quien generalmente la refrenda.

26 Según las mismas funcionarias, ellas le brindan apoyo a las víctimas del maltrato; en ese apoyo incluyen referencias a Dios, a que las cosas pasan por algo, y a que hagan algo para mitigar el conflicto, entre otras.

A pesar de que la Ley 1257/08 hace obligatoria la denuncia de parte del funcionario, de delitos conexos a la violencia intrafamiliar (constreñimiento ilegal, acceso carnal, etc.) que es igualmente un delito. 
Es importante hacer ver el papel tan relevante del auxiliar administrativo, quien por lo demás, no aparece entre los funcionarios que determina la ley. Como se aprecia en el relato anterior, el auxiliar administrativo es, hasta cierto punto, un actor fundamental en el acceso de la víctima a la protección que la ley provee pues funciona no como un simple tramitador sino como alguien con un nivel de decisión muy importante.

En el tercer piso también hay prevista una psicóloga para atender a las personas de manera inmediata. Sin embargo, en las cinco visitas que se realizaron en distintas horas, solo en la cuarta se logró conocerla porque en las otras ocasiones no se encontraba o estaba ocupada.

De lo anterior se puede concluir que las víctimas-usuarios de la Comisaría deben estar preparadas para permanecer al menos dos horas haciendo los trámites de presentación de la denuncia, abstenerse de llevar a sus hijos (si no tienen con quien dejarlos es muy difícil que vayan $)^{28}$, y finalmente, relatar lo sucedido casi tres veces antes de acceder al funcionario que por ley es el único competente y el único que debería conocer de los hechos: el comisario de familia. Sólo si el caso es muy grave ${ }^{29}$, la o el comisario atiende a la víctima inmediatamente, decreta medidas de protección de manera temporal, y cita para audiencia de conciliación y pruebas; en esta audiencia se dictan las medi-

28 Sin embargo, la mayoría de mujeres que se encontraban allí para hacer denuncias de violencia doméstica llevaban niños, generalmente de brazos o muy pequeños.

29 Más adelante se precisa qué es lo que los comisarios de familia definen como muy grave. das de manera definitiva. Al respecto caben las declaraciones del comisario $\mathrm{CM}$ :

"todo depende del concepto y el profesionalismo de la persona que está en recepción que más o menos dice a dónde va el caso, si a conflicto o violencia, ellos dan un concepto inicial".

\section{La violencia es...}

Una vez dentro del sistema de protección, es decir, validado el caso por el funcionario administrativo, toma validez el concepto sobre quién es víctima de violencia intrafamiliar ${ }^{30}$ :

Para la comisaria CG:

“(...) cuando se ejerce una violencia física, verbal o psicológica seria, en contra de la víctima y es una situación recurrente"31

\section{Según el comisario CM:}

"todos los casos los podríamos catalogar como de violencia intrafamiliar, (...) lógicamente lo que la ley 294, reformada por la 575 buscó, era que todo caso de vulneración, no sólo desde el punto de vista físico, sino también moral o psicológico se convierta en caso de violencia intrafamiliar, (...), desde el criterio que orientan allá abajo (se refiere a la recepción) se mira si el evento que nos están reportando no es un

30 La ley 575 del 200 la define como: Art. 1. Toda persona que dentro de su contexto familiar sea víctima de daño físico o psíquico, amenaza, agravio, ofensa o cualquier otra forma de agresión por parte de otro miembro del grupo familiar, [que] podrá pedir, sin perjuicio de las denuncias penales a que hubiere lugar, al Comisario de familia del lugar donde ocurrieren los hechos y a falta de éste al Juez Civil Municipal o promiscuo municipal, una medida de protección inmediata que ponga fin a la violencia, maltrató <sic> o agresión o evite que ésta se realice cuando fuere inminente.

31 Para esta comisaria la reiteración de la violencia tiene que existir porque de no ser así se maneja como conflicto y no como violencia. 
evento aislado, sino que es una situación repetitiva, en donde haya un riesgo para la integridad de la persona, en donde inclusive hayan lesiones personales como tal, ahí es donde decidimos que el caso se maneja por violencia intrafamiliar, (...) si ven (las personas que atienden en recepción) que no es un hecho aislado, sino que se está presentado muy continuamente o hay amenazas contra la vida de la persona, ahí sí se debe manejar por violencia intrafamiliar, (...) es lo más importante para nosotros, que sean situaciones repetitivas, o que la violencia sea tal que se necesite imponer algo mucho más drástico para impedir que los hechos de violencia continúen presentándose, eso está más en consideración de los hechos que se estén presentando (...). (...) Es más por la conveniencia que nos ofrece la posibilidad de poder sancionar el hecho repetitivo de violencia, (...) porque todos los casos de violencia se tienen que llevar por el comisario, a diferencia de los casos de conflicto que sí pueden ser llevados por el psicólogo o el trabajador social de la Comisaría y ellos pueden abordarlo e inclusive amonestar al agresor."

Así, es posible afirmar que los hechos de violencia importan, pero importa muchísimo más que sean repetitivos y graves. Primero se tiene que pasar la barrera del auxiliar administrativo y luego la del comisario, quien si no es un hecho repetitivo no lo atiende sino lo remite a los trabajadores sociales o a los psicólogos de la Casa de Justicia. De esta forma, así la ley no diga que los hechos tienen que ser repetitivos, la práctica en la Comisaría de Familia dice que es necesario que así sean. Esto se puede corroborar con el hecho de que, de los muchos casos de violencia que atendieron en la Comisaría de Suba en las dos semanas que estuvimos realizando el trabajo de campo, sólo dos llegaron a medidas de protección. Eso significa que se prefiere llamar conflicto a los casos de violencia doméstica y tratarlos según el Código de Policía ${ }^{32}$.

De igual forma, en la entrevista a los comisarios se puede evidenciar la diferenciación que estos hacen entre violencia física y violencia psicológica. A la pregunta: ¿Ha tenido casos de violencia no física y cuál es el porcentaje de los mismos?, las respuestas fueron:

CG:

"Sí claro, está la violencia verbal, la psicológica, que en mi sentir es mucho más grave, [es] cuando se valen de artimañas para desempoderar a la otra parte, tales como: las continuas amenazas de que la va matar, de que le va a quitar los hijos y se los va a llevar, de que la va a encerrar, que no vale nada, que es una basura. (...) diciéndole que es una perra, que es una gran no se qué, es gravísimo. El porcentaje puede ser un 30\%."

CM:

“(...) hay muchos casos de violencia verbal, psicológica; si hablamos de porcentajes el $60 \%$ es física, el 30\% verbal y el otro 10\% psicológica. Pero es muy difícil comprobar la violencia psicológica, (...)"

¿Cómo se evalúan los casos de violencia sicológica?

32 Esto será tratado más adelante, en el subtitulo Eso no es violencia, es conflicto. 
CG:

"Con relación al escrito que presenta la víctima y en muchas ocasiones con el apoyo de [la oficina] de psicología."

¿Qué medidas de protección se decretan en esos casos?

CG:

"Los mismos, que en cualquier caso. No hay distintigos (sic), pero se hace necesario valorar la gravedad de los hechos que se están denunciando para tomar las medidas."

CM:

"Más que todo buscar el tratamiento con un psicólogo o con un psiquiatra si no cualquier medida es insuficiente, porque cualquier cosa que se haga sin eso no sirve, (...) Y lo otro es que es muy difícil que el agresor acepte que es agresiva para la psiquis del otro".

Como se observa, la violencia psicológica existe pero es difícil de probar, no es tan evidente como la física, exige pruebas de mayor desarrollo y se necesita una decisión cuidadosa. Ejemplo de esto es el relato de la comisaria G sobre el caso de un señor que utiliza el sistema de protección de manera arbitraria: "el señor se presenta ante la Comisaría y pide la medida de protección de desalojo de su pareja, porque ella decidió poner su ropa en el armario más pequeño y esto lo afectaba psicológicamente, para lo cual allegó pruebas". Para el comisario G, no existía razón en el usuario y nunca decretó tal medida, motivo por el cual el quejoso denunció disciplinaria- mente a la funcionaria, proceso que está siendo decidido en estos momentos.

\section{Lo que importa son los hechos}

En las entrevistas con los comisarios de familia de Suba se da una similitud cuando se les pregunta qué motiva el decreto de una medida de protección. En general, se podría decir que los hechos son fundamentales, que cada caso es único y muy distinto de otros, es decir, así los hechos de violencia sean los mismos (por ejemplo un ojo morado, una incapacidad de 10 días, una quemada) no se decide igual.

CG:

“(...) cada caso es completamente distinto, no se pueden aglomerar todos dentro de lo mismo, así la violencia física haya sido realizada de la misma forma, los antecedentes del mismo son bien distintos, por eso la motivación de la providencia se va con fundamento en todo lo que se pueda evidenciar (...), dependiendo de la gravedad, porque la providencia puede llegar a ser desde una conminación hasta un desalojo inmediato del sitio de habitación, la prohibición de que permanezca en la localidad, en fin. Todo tipo de medidas que propendan para que la víctima tenga la seguridad que se pretende".

CM:

"Nosotros motivamos la medida de protección, no solo de acuerdo a la normativa, sino a cada caso específico, y en lo que cada uno reporte en la audiencia como tal, yo trato de basarme no tanto en el escrito presentado inicialmente, si no en la audiencia, donde cada uno de ellos me expresa, (...)". 
Pero lo anterior tiene que ser matizado con la respuesta a la pregunta: la ley no señala que deba hacer una investigación de la historia de la víctima ¿le parece pertinente hacerla, o sólo importa el hecho puntual objeto de la queja? ¿La ha hecho en algunos casos?, ¿por qué? Los comisarios contestaron así:

CG:

"Sí se hace una investigación de la historia de la víctima, tomando en consideración (...) aspectos puntuales como: la relación de pareja desde sus inicios, cómo se ha manejado esta, si la víctima durante su niñez al lado de sus padres, también fue tratada de esa forma y los aspectos que hacen pertinente investigar si sicológicamente existe una afectación desde mucho antes, y esto es lo que ha conllevado a que se deja maltratar de esa manera, (...) Es muy importante el hecho puntual, pero también lo es lo acontecido anteriormente, para poder emitir un fallo conforme a las necesidades, no yéndonos únicamente por lo puntual de la queja."

CM:

"Inicialmente, cuando se dan las situaciones no se mira para nada la historia de la persona que viene a poner la queja, inclusive muy poco se mira el historial o el entorno en las audiencias, de pronto nuestra formación a nivel de Comisaría es que en las audiencias siempre se pregunte por muchas de las cosas por las que ha pasado, del por qué, si ha habido hechos de violencia antes, (...) yo creo que eso se debe hacer en terapia, porque en muchos de los casos no reconocen en una audiencia al frente de la víctima o del agresor, yo pregunto muchas de esas cosas a la gente, qué ha pasado, por qué cree son así, por qué se presentan los celos, y las personas hablan pero no es lo común en una audiencia."

En resumen, la revisión de las historias de vida de los usuarios es importante para ambos comisarios, pero sólo para CG es fundamental y, además, tienen que ver no solo con el hecho de violencia sino con que se permita la misma. Para GM importa sólo lo que se descubre en las audiencias, reconoce el valor de esos hechos en procesos terapéuticos pero no para él ni para la Comisaría.

Se puede ver, entonces, que una de las cosas que incide en la decisión de los comisarios es la forma en que se aproximan a los hechos, el estudio juicioso o no de la historia, el contexto de la víctima y el del agresor. En la codificación de las entrevistas se logró dar cuenta de que algunas circunstancias como el alcohol, el hacinamiento, el desempleo, entre otras, son determinantes para definir la acción a seguir: si se manda a terapia a Alcohólicos Anónimos, si se remite a uno de los proyectos del Centro Operativo Local en busca de empleo, etcétera, todas como disposiciones accesorias a la decisión de medida de protección. Igualmente, esas circunstancias no son concluyentes para la forma en que se decreta una medida de protección.

Otro punto que arroja el análisis de las entrevistas, es lo que para ellos significa la medida terapéutica y reeducativa. Aunque en la ley está contemplada como una de las medidas de protección que puede decretar el funcionario, los comisarios la perciben como medidas de oficio que siempre se decretan. A su juicio sólo son 
medidas de protección las impositivas, las que se pueden hacer exigibles y se pueden convertir en incidentes de incumplimiento, convertibles en multas o en días de arresto.

CG:

“Un proceso terapéutico es el que nos da las pautas (...), en el evento que uno evidencie que existe algún grado de afectividad entre las partes y lo que pasa es que hay una comunicación inadecuada o son pautas de crianza las que llevan a esas situaciones de violencia."

Sobre si decreta la medida terapéutica:

CG:

"Constantemente, en un 98\% de los casos, se ordena que las partes acudan a este proceso, en ocasiones únicamente al agresor (...), aunque generalmente es a las partes, puesto que estos episodios de agresión a mi juicio son por una inadecuada educación o un inadecuado rol, pautas de crianza inadecuadas, una historia de vida que genera una víctima y un victimario."

CM:

“Siempre, en las medidas de protección, uno (...) trabaja sobre formatos prácticamente, hay puntos de la parte resolutiva del formato en donde en casi todos los casos está el tratamiento reeducativo y terapéutico, a mucha gente le da miedo, porque digamos el agresor cree que lo van a acusar. Es el trabajo que uno haga, y lo muestre no como una obligación, sino como un mecanismo para superar los problemas."
Sobre si decreta la medida en contra de las partes:

CM:

"Si hay niños y/o adolescentes involucrados sí, si son mayores y la pareja no lo quiere, no lo ordeno. Me parece que si no hay conciencia mejor no se hace, la gente tiene que tener voluntad sino, no sirve."

\section{La perversión de las medidas de protección}

Los dos comisarios (CM y CG) concuerdan en la peligrosidad de la amplitud de la ley porque permite que muchas personas accionen el sistema de protección sin razones, sin necesidad o por eventos de distinta naturaleza, al no tipificar los casos de violencia y al convertir en beneficiarios de la ley a "cualquier persona que dentro de su contexto familiar sea víctima de daño físico o psíquico, amenaza, agravio, ofensa o cualquier otra forma de agresión por parte de otro miembro del grupo familiar".

Respecto, por ejemplo, de la medida de desalojo:

CG:

"[Tiene] un grado de responsabilidad muy grande de parte de nosotros, porque tiene que evidenciarse que esa violencia es cierta y [apreciar] unas pruebas contundentes frente a eso, porque también las Comisarías de Familia somos tomadas por algunas personas como el sitio más fácil para sacar a una persona de su sitio de habitación y así presentan medidas de protección sin justificación, en donde son absolutamente claros en que lo único que 
pretenden es el desalojo para evitarse procesos civiles largos, entonces el funcionario tiene que ser muy prevenido. Si bien, es cierto que es una medida muy importante, también es cierto que es muy delicada y que se deben tomar todo tipo de evidencias para no vulnerar derechos de otra persona".

CM:

"los abogados o usuarios que saben de la medida la usan como herramienta para facilitar procesos más largos, como cuando no se pueden solucionar problemas de sociedades conyugales o de partición, se busca la medida de protección para eso, y se debe mirar el trasfondo para mirar si hay mérito de la aplicación de la medida de protección".

De esta manera, el desalojo se convierte en una forma de abuso del derecho por parte de algunos usuarios; frente a esta medida los comisarios son muy cautelosos y revisan muy bien los hechos para no cometer arbitrariedades que degeneren en injusticias. Por esta razón, la medida de desalojo no es muy utilizada por las Comisarías aunque sea ampliamente publicitada y en la legislación colombiana sea vista como la medida estrella en casos de violencia intrafamiliar.

Un trabajo interinstitucional

Los comisarios coinciden en que el trabajo con otras instituciones, tales como la Policía, las entidades de salud (IPS y EPS), los jueces, entre otros, ha sido de muy difícil implementación. Algunas veces porque no hay personal suficiente para responder o no hay manera de compartir la información para que exista retroalimentación y así saber si la medida adoptada funciona sin necesidad de un seguimiento por parte de la Comisaría. A la pregunta ¿Cómo siente que es el trabajo en coordinación con otras entidades del Estado como entidades de salud, policía o jueces?, las respuestas fueron:

CG:

“Debería ser coordinado pero no lo es, (...) hemos tenido dificultades de todo tipo, en la policía es muy poco el personal, por ejemplo acá en esta localidad sólo hay una patrulla para infancia y adolescencia, para que la policía metropolitana haga un desalojo, es bien complicado, toca ejercer mucha presión, hacer un oficio que tiene que ser avalado por el comandante de policía, en muchas oportunidades llega el día del desalojo y no se cuenta con transporte para ir a realizar la diligencia. Con salud no hay mecanismo de comunicación directa, no hay un buen trabajo interinstitucional".

"Hay una carencia para poder implementar un trabajo terapéutico posterior al fallo de medida de protección, en donde exista una comunicación permanente con quien esté realizando este trabajo y la Comisaría, y se vea el fruto, si bien es cierto que ordenamos la remisión al trabajo terapéutico lo hacemos por intermedio de las EPS, ARS, o el Hospital de Suba, siendo conocedores ampliamente de que hoy en día, los profesionales en salud cuentan con 10 o 15 minutos para atender a los usuarios, les alcanzan a preguntar lo general y ya. Entonces no es un trabajo asertivo y en ocasiones, tenemos apoyo de unas ONG, como Sistemas Humanos, FundaTerapia, que realizan un trabajo excelente, (...)" 
“No es fácil, cada uno tiene su propio código y sus propias normas, y eso es lo que es difícil, si analizamos la nueva Ley de Infancia y Adolescencia cada uno le da una interpretación diferente, así (...) no hay articulación, igual ahora es mejor que antes pero no es tan sencillo, hay más diálogo, pero para esta época no hemos podido armonizar la atención y hacer un andamiaje, en donde cada uno sea punto de apoyo del otro".

De esta forma, las pretensiones de la nueva ley en cuanto a armonizar y poder crear una organización completa capaz de manejar los problemas de la violencia doméstica no se han cumplido, pues el trabajo ha sido difícil, sobre todo con la Policía ${ }^{33}$; de otra parte, la falta de trabajo interinstitucional hace que las medidas de protección decretadas sólo puedan tener seguimiento y ser evaluadas cuando el comisario ordena la movilización de uno de sus funcionarios para hacer visitas y entrevistas, lo cual resulta aparatoso, lento, costoso y, por ende, ineficaz.

\section{Eso no es violencia, es conflicto}

La anterior explicación sobre lo que los comisarios consideran como violencia, introduce una nueva pregunta: ¿Qué debe hacerse en los casos en que no hay violencia intrafamiliar sino más bien conflicto?
CM:

"podíamos manejar muchos de los casos como conflictos familiares, lógicamente lo que la ley 294, reformada por la 575 buscó, era que todo caso de vulneración, no sólo desde el punto de vista físico, sino también moral o psicológico se convierta en caso de violencia intrafamiliar, (...) pero nosotros lo manejamos a través de conflicto por el Código de Policía. Buscando no llevarlo todo a la violencia familiar, porque esa tiene un procedimiento legal que hay que respetar y las decisiones se hacen en tal evento con las medias provisionales en 4 horas y definitivas en 10 horas, lo cual sería infernal para las personas que estamos trabajando esto, porque no habría espacio para nada, todo lo tendríamos que hacer corriendo. $Y$ hay casos que no necesitan llevarse así, digamos hay casos donde hay hechos de violencia pero son circunstancias que se presentaron un día y no se han vuelto a presentar más, entonces por qué llevar a un caso de violencia si se puede manejar como una caución de comportamiento o una amonestación para evitar hechos repetitivos,(...), nosotros antes teníamos lo que llamábamos "los intolerables" que era como un filtro, que se basaba en nuestra experiencia

33 El papel de la Policía en la aplicación de la medida de protección del Comisario es fundamental, pues esta institución es la que puede verificar y sancionar el incumplimiento de manera inmediata. 
para saber qué casos llevamos a que sean violencia intrafamiliar y cuáles no, porque todos los casos de violencia se tienen que llevar por el comisario, a diferencia de los casos de conflicto que sí pueden ser llevados por el psicólogo o el trabajador social de la Comisaría y ellos pueden abordarlos e inclusive amonestarlos.

"[una diferencia] entre conflicto y violencia, en violencia se debe fallar hasta dentro de 10 días, mientras que en conflicto se da una cita en 20 días o más dependiendo el caso".

Con esta forma de interpretación de la ley no son extrañas las cifras que ofrece Pineda (2004, p: 11):

"según la Secretaría de Gobierno del Distrito Capital, para el 2002, de los 87.466 usuarios registrados por las 20 Comisarías de Familia en Bogotá, 47.980 (54.9\%) realizaron audiencias de conciliación, compromiso y protección. De estos últimos, 26.135 (54.5\%) presentan hechos de violencia y de estos casos sólo el $4 \%$, son tramitados a través de medidas de protección bajo la ley 575" (negrillas fuera del texto).

Al actualizar los datos con las cifras más recientes de la Secretaría de Integración Ciudadana -SIC- se tiene que para el 2008 de las 56.321 demandas de violencia intrafamiliar en Bogotá, 44.416 fueron tramitadas como conflicto familiar y tan sólo 9.114 Ilegaron a constituir violencia intrafamiliar; específicamente para Suba, de las 7.433 demandas de violencia intrafamiliar tramitadas en las tres comisarias de la localidad (1, 2 y 3), 6.099 constituyeron conflicto familiar y tan sólo 923 se convirtieron en violencia intrafamiliar con medidas de protección, es decir, el
$12 \%$ de las demandas llegan a tener medidas de protección, mientras que el $82 \%$ son calificadas como conflictos; el porcentaje restante (6\%) corresponde a casos de maltrato infantil.

\section{Para un conflicto se necesitan dos}

En los relatos de los dos comisarios cuando se aproximaron a la pregunta sobre si consideraban que existiera un tipo de corresponsabilidad entre la víctima y el agresor, con mucha seguridad respondieron que sí:

CG:

"Sí, es muy frecuente, porque en las situaciones de agresión se requiere la responsabilidad de dos o más personas, se requieren dos para un conflicto no uno sólo, obviamente uno tiene un grado de responsabilidad mucho mayor que el otro".

CM:

"Sí, de pronto las personas que vienen acá a la Comisaría dan su punto de vista de lo que se ha presentado como tal, pero ya cuando las personas están en una audiencia, ya uno se da cuenta que, en muchas oportunidades, muchas de las reacciones del agresor son inclusive provocadas, hay responsabilidad del uno como del otro, (...), la mujer por lo general no pega, pero cuando hace daño, hay muchas personas que cantaletean y la reacción del hombre es violenta. Mucho es porque hay alcohol (...), se han tomado 3 tragos y ahí es cuando reaccionan, pero el grado de agresividad del hombre es más alto que el de la mujer. No por eso se está justificando la agresión, no es que les peguen porque los provoquen, (...) 
esta semana [una] señora decía que era la que lo había provocado, le preguntaba por la moza, él quería salirse, ella se le paró en la puerta cogió un palo y él se desesperó y "tácate" ahí fue cuando recibió el golpe. Hay que buscar que la víctima no justifique el actuar de la persona, incriminándose a ella misma, pero en este caso es cierto, porque fue por la insistencia de ella, entonces sí hay una corresponsabilidad."

Así las cosas, se asume que no se generan conflictos sin la intervención del otro, inclusive en los casos donde hay alcohol se habla de corresponsabilidad, pues el hombre se desahoga por estar desinhibido. Sin embargo, CM es enfático al decir que no es que se justifique al agresor, pero sí cree que la actitud de la víctima en muchas ocasiones sirve como detonante de problemas ya sean psicológicos o en muchos casos económicos del agresor. Ninguno de los comisarios se refiere a casos donde la persona simplemente no actúe como le ordena el agresor y por eso se convierta en víctima, pues siguiendo los planteamientos de Lemaitre (2002, p: 76 y ss.) la violencia es usada como un mecanismo de control del cuerpo y es una de las formas más efectivas de mantenimiento de la pirámide jerárquica que tiene como jefe supremo a los varones.

\section{CONCLUSIONES}

Con anterioridad se presentaron algunas de las conclusiones que arrojaron las entrevistas. Sin embargo, es pertinente introducir unas hipótesis que aunque arriesgadas por el uso de solo dos herramientas metodológicas, no parecen tan descabelladas según la información recolectada y permiten presentar unas propuestas de investigación futura, bien sea para confirmarlas o rebatirlas.

En relación con el acceso a la Comisaría de Familia de Suba, se logró identificar una serie de procedimientos y de intermediarios que la ley no contempla, pero que tienen un papel fundamental a la hora de determinar la categoría en que se va a situar la petición de protección (conflicto o violencia intrafamiliar). El auxiliar administrativo es uno de ellos, no sólo por ser el primer funcionario de la Comisaría al que la víctima logra acceder, sino porque tiene un rol decisorio respecto al curso de acción tanto del comisario como de la víctima.

En cuanto a la definición de violencia intrafamiliar que utilizan los comisarios, se evidenció que ésta es mucho más restringida que la que la ley ofrece; en principio porque incluye la reiteración y gravedad como nuevos elementos para determinar si los sucesos constituyen un caso de violencia y no de conflicto. Esto se relaciona con el hecho de que a los comisarios parece no gustarles mucho trabajar casos de violencia intrafamiliar y prefieren calificarlos como conflicto familiar para distribuir la carga entre todo el personal de la Comisaría. Por el mismo camino estaría el problema de la amplitud de la ley, pues en concepto de los comisarios, tanta libertad para actuar, al contrario de propiciar funcionarios y decisiones más creativas, les parece peligroso y preferirían una ley taxativa incluso si resultara restrictiva. Ello ha hecho posible que algunos usuarios y abogados utilicen las medidas de protección como forma más rápida para obtener 
respuestas del Estado, en casos que implicarían procesos civiles largos (como la liquidación de sociedades conyugales). Estos usos vician el espíritu de la medida de protección, especialmente la de desalojo, en tanto la convierten en una medida que requiere responsabilidad de parte del comisario y no es fácil que en efecto se decrete; a pesar de ser vista como una disposición buena y efectiva no es la más utilizada.

También se podría agregar el hecho de que la medida de protección reeducativa y terapéutica es percibida como un relleno, se decreta en todos los casos salvo que las partes se opongan expresamente, y es una de las mejores salidas a los problemas de violencia. Sin embargo, cuando se les pregunta por el apoyo interinstitucional para los servicios de terapia que se ofrecen (EPS, ARS, Hospital de Suba nivel II, entre otras) se muestran muy inconformes con el trabajo que estas entidades realizan. Así, se evidencia una desconexión entre la que les parece una de las mejores medidas y los posibles resultados de la misma, dado el mal trabajo de las instituciones que ofrecen el servicio terapéutico.

Por otro lado, la importancia de los hechos para decidir en un caso de violencia intrafamiliar, el tipo de medidas que se decretan y los hechos que cada una de las partes relatan bien sea en la audiencia de conciliación o en el RUG, son definitivos para decidir el tipo de agresión. Los comisarios insisten en que los hechos determinan todo, que no hay analogías posibles. Esto es perfectamente entendible, pues por semana se tienen aproximadamente tres casos de violencia intrafamiliar que deben ser atendidos directamente por el comisario, frente a muchos conflictos familiares que son remitidos a otros funcionarios. Algo que merece atención es el hecho de que los comisarios trasladen a los usuarios la potestad que les otorga la ley de hacer "Io que crean pertinente" para acabar con los hechos de violencia y les parezca que lo mejor es que ellos mismos construyan sus rutas de resolución del conflicto.

Otro tema importante es la dificultad que reconocen los comisarios para identificar los casos de violencia cuando ésta sólo es psicológica; además, la ley no define cómo debe ocurrir. Al respecto, son pertinentes las apreciaciones de Jaramillo (1999, p: 69) sobre el lugar que la Corte Constitucional le da a la violencia psicológica, al decir que continúa estando en lo privado y cómo los fallos de tutela serían favorables sólo si se presentara violencia física y reiterada. Esta interpretación de la Corte la compartirían los comisarios al referirse a su dificultad en materia probatoria y las pocas decisiones en casos de este tipo.

Un aspecto que tiene relación con todo lo anterior es la fórmula de convertir las demandas de violencia intrafamiliar en conflicto familiar para tramitarlas con un procedimiento menos rígido y, en términos de CG, menos legal, en el que pueden participar más personas que en la violencia intrafamiliar de la ley 575 , pues el conflicto tiene unas medidas que necesitan menos motivación y son menos certeras.

Otro hecho importante pero que no se refleja claramente en las entrevistas, es que los comisarios piensan que cada localidad tiene sus 
propios problemas y las diferencias son manifiestas. Para CG, en Suba hay muchos problemas siquiátricos y económicos, mientras que en San Cristóbal, donde fue comisaria antes, había mucha infidelidad. Esto modifica las formas en las que se aproximan a los casos, porque se puede suponer que después de saber cuáles son los problemas de "cada localidad" les resulta fácil hacer que el caso sea de violencia o de conflicto si responde a la problemática propia del lugar.

Por otro lado, es posible dar cuenta de cómo los comisarios muestran un especial interés en el tema de la corresponsabilidad entre víctima y agresor, sin embargo no se evidencia que eso modifique la forma en la que deciden sino al hecho de que la ley no les ofrece herramientas para matizar un fallo de este tipo. Parece inadecuado que la misma ley culpabilice a la víctima, pues en términos de Lemaitre (2002, p: 77) esa idea de que si la víctima persiste en el lugar donde es maltratada, es porque lo desea o sencillamente la propicia, lo que facultaría al Estado para no intervenir por ser una relación sádicomasoquista, en la que ambas partes participan voluntariamente. Lo anterior está ampliamente difundido y es muy perjudicial pues desconoce las pugnas de poder, control y dominación que ocurren al interior de la familia.

Asegurar que se puede predecir la decisión cuando se presentan circunstancias como alcohol, desempleo, hacinamiento, corresponsabilidad, armas o inclusive violencia grave, es complicado ${ }^{34}$, porque las entrevistas no llevan a tal conclusión. Es trabajo de una investigación futura lograr aproximarse a los expedientes tratando de ser muy cuidadosos con los hechos, para confirmar con una fuente más 'objetiva' lo que acá los comisarios contestaron.

Por todo lo anterior, es visible la incapacidad del derecho para articular las necesidades de las víctimas, las normas aplicables y las dificultades para ponerlas en práctica, los operadores extrajurídicos que interfieren, las dificultades propias de la cultura tanto de los agresores como de las víctimas al interferir en la aplicación de la ley, y la tradición jurídica formalista que impide que la amplitud de la norma sea vista como un aspecto positivo que permitiría tomar decisiones diversas, diferenciadas y ajustadas a hechos particulares.

En Colombia existe un conflicto y en este "contexto cuyos factores de violencia siguen presentes, las víctimas y las comunidades desarrollan estrategias de supervivencia y de resistencia, más que de transformación de los poderes (...)" (Sánchez, 2008: p. 25). Aunque lo anterior se afirma en el proceso de construcción de memoria sobre la masacre de Trujillo (Valle del Cauca), ocurrida en Colombia en 1990, es un ejemplo de cómo la violencia típicamente pública-política y la violencia típicamente privada-intrafamiliar se vinculan, pues sus víctimas utilizan repertorios

34 El único factor que modifica sustancialmente la decisión de los comisarios es la presencia de niños, niñas o adolecentes, pues cuando hay hijos de por medio obligan a las partes a acudir a terapia, piensan más de dos veces antes de decretar el desalojo, pero no por consideración con los lazos de paternidad pues de hecho creen que esta medida los fortalece, sino para no tener que imponer alimentos y visitas porque, en su concepto, esto vuelve más violento al agresor. 
emocionales similares, no transforman el poder al que son sometidas, y las formas jurídicas vigentes que ofrece el derecho, no les son suficientes.

\section{Bibliografía}

BOLIVAR, Ingrid. 2006. Discursos emocionales y experiencias de la política. Las Farc y las AUC en los procesos de negociación del conflicto (1998-2005). Bogotá: Centro de Educación Popular CINEP-Ediciones Uniandes.

CAMACHO, Álvaro. 2006. "De narcos, paracrasias y mafias" en Leal Buitrago, Francisco. (Editor). En la encrucijada: Colombia en el siglo XXI. Bogotá: Ediciones Uniandes.

CASTELLANOS, Gabriela; Rodríguez, Alba y Bermúdez, Norma. 2001. “Mujeres y conflicto armado" en Castellanos, Gabriela y Accorsi Simone. (Comp.). Sujetos femeninos y masculinos. La Manzana de la Discordia. Cali: Centro de Estudios de Género, Mujer y Sociedad, Universidad del Valle.

GALVIS, Ligia. 2001. La familia: una prioridad olvidada. Bogotá: Ediciones Auros.

GUILLÉN, Fernando. 1996. El poder político en Colombia. Bogotá: Editorial Planeta.

JARAMILLO, Isabel Cristina. 1999. “El hogar ¿espacio privado o público? A propósito de la jurisprudencia de la Corte Constitucional colombiana en materia de violencia contra las mujeres de parte de sus esposos o compañeros permanentes" en Cepeda, Manuel
José. (Comp.). Derecho Constitucional. Perspectivas críticas: ensayos, líneas jurisprudenciales, balance estadístico. Bogotá: Siglo del Hombre Editores-Facultad de Derecho Universidad de los Andes.

LEAL, Francisco. 2002. La seguridad nacional a la deriva. Del Frente Nacional a la Posguerra fría. Bogotá: Alfaomega.

LEMAITRE, Julieta. 2003. Efectividad de las medidas de protección y la conciliación en situaciones de violencia intrafamiliar. Bogotá: CIJUS, Universidad de los Andes.

_ 2002. "Justicia injusta: una crítica feminista a la conciliación en violencia conyugal" en Revista de Derecho Privado No. 27, febrero de 2002. Bogotá: Universidad de los Andes.

PALACIO Cepeda, Marisol. 2008. La violencia intrafamiliar: teórico-práctico. Bogotá: Leyer.

PINEDA, Javier y Otero Peña, Luisa. 2004. "Guerra en los hogares: género, violencia intrafamiliar e intervención pública en Colombia" en Revista de Estudios Sociales No. 17, febrero de 2004. Bogotá: Facultad de Ciencias Sociales, Universidad de los Andes.

_ 2003. "Poder de negociación y violencia intrafamiliar. ¿Qué tanto de conciliación? ¿Qué tanto de protección?" Ponencia presentada en el Foro Internacional sobre Familia, Derechos Humanos y Democracia. Próximo a publicarse. 
ROMERO, Mauricio. 2006. "Paramilitares, narcotráfico y contrainsurgencia: una experiencia para no repetir" en En la encrucijada: Colombia en el siglo XXI. Bogotá: Facultad de Ciencias Sociales, CESO, Universidad de los Andes.

_ 2005. "La desmovilización de los paramilitares y autodefensas: riesgosa, controvertida y necesaria" en Síntesis: anuario social, político y económico. Bogotá: Fescol, lepri, Nueva Sociedad.

SÁNCHEZ, Gonzalo. 2008. "Introducción" en Trujillo: una tragedia que no cesa. Primer informe de memoria histórica de la Comisión Nacional de Reparación y Reconciliación. Bogotá: Editorial Planeta.

Normas

Colombia. Constitución Política de 1991, artícuIo 42.

Ley 294 de 1996.

Ley 575 de 2000.

Decreto 652 de 2001.

Ley 1257 de 2008.

\section{Páginas Web}

www.profamilia.org

www.visionofhumanity.org www.angelcustodiocabrera.com

http://relatorestematicos.uniandes.edu.co/index.php/es/violencia-intrafamiliar.html

Anexo 1: Códigos y cuestionarios

Usuarios

1. ¿Qué tipo de población atienden? ¿Estrato, género, raza, orientación sexual?

2. ¿Cuáles son los patrones culturales de la población que atiende? (¿quién sostiene económicamente?, ¿cómo son los roles?)

3. ¿Cómo se enfrentan al patrón cultural según el cual el hombre es el proveedor?, ¿esto modifica la forma de decisión?

4. ¿Qué pasa con la mujer si se queda sola por la aplicación de una medida de protección, como por ejemplo el desalojo?

5. ¿Cómo y cuándo se determina que una persona ha sido víctima de violencia intrafamiliar?

6. ¿Cree que en algunas situaciones se da una corresponsabilidad entre las actuaciones de la víctima y el agresor?, ¿cuáles?

7. La ley no señala que deba hacer una investigación de la historia de la víctima.

a. ¿Le parece pertinente hacerlo, o sólo importa el hecho puntual objeto de la 
queja? ¿La ha hecho en algunos casos? ¿por qué?

8. ¿Cree que existen situaciones que hagan más posible la violencia? ¿Cuáles?

9. ¿Existe alguna relación entre personas que consumen alcohol y los niveles de violencia que presentan? Es decir, ¿es común que el agresor haya estado bajo los efectos del alcohol y a eso se deba su conducta violenta?

a. ¿Influye esto en la medida de protección que decreta?

10. ¿Existe alguna relación entre la violencia intrafamiliar y el desempleo?

a. ¿Es más común que quien quede desempleado se vuelva violento?

b. ¿Afecta esto la medida de protección decretada?

11. ¿Existe alguna relación entre violencia y hacinamiento?

a. ¿Es más común que grupos familiares que viven hacinados presenten conductas violentas?

12. ¿Ha recibido algún caso de violencia intrafamiliar en parejas del mismo sexo?

a. ¿Considera que los hechos que generan la violencia son iguales a los de parejas de distinto sexo?
13. ¿Usted cree que hay usuarios que sabotean las medidas de protección? ¿Cómo lo hacen? ¿Hay alguna respuesta institucional?

14. ¿Qué términos utilizan para referirse a las partes en la audiencia?

15. ¿Qué pasa cuando al agresor no le importa ningún tipo de medida que pueda adoptarse, ni siquiera la cárcel?

16. ¿Es diferente el trato y las medidas decretadas cuando se trata de un caso nuevo y cuando es un caso reincidente?

17. ¿Ha tenido casos de violencia no física?

a. ¿Cuántos casos llegan que no son de violencia física?

b. ¿Cómo se evalúan los casos de violencia sicológica?

c. ¿Qué medidas de protección se decretan en esos casos?

\section{Medidas de protección}

1. ¿Cómo motiva la providencia?

2. ¿Alguna vez ha conminado a algún agresor?

a. De responder sí: ¿lo hace acompañada de otras medidas o no necesariamente y por qué?

b. De responder no: ¿por qué? 
3. ¿Alguna vez ha decretado la medida de desalojo?

a. De responder sí: ¿Con base en qué tipo de hechos toma la decisión de ordenar un desalojo?

b. ¿Cómo funciona?, ¿por cuánto tiempo?

c. ¿Se ordena el desalojo sólo del agresor? ¿En qué condiciones se decreta el desalojo de la víctima? ¿Por qué?

d. ¿Qué le parece esta medida? ¿Por qué?

e. ¿Qué hacen para que, una vez ordenado el desalojo, no se rompa la relación si las partes no quieren que eso pase?

f. ¿En un caso donde el agresor es desalojado, abandona emocional y materialmente a los hijos y a los que quedan en general?, ¿cómo hacen para prevenir esto?

g. ¿Cree usted que la medida de desalojo sacrifica el vínculo paterno? ¿La presencia de niños determina el tipo de medida que se decreta?

h. ¿Existe alguna manera de hacer un desalojo progresivo, como que sea sólo definitivo la tercera vez que vuelve a reincidir?

i. De responder no: ¿Por qué?
4. ¿Ha ordenado alguna vez la "caución" para evitar que el agresor perturbe, intimide o amenace a la víctima?
a. SÍ: ¿Esta medida implica el desalojo?
b. ¿Con qué hechos decide decretar la "caución"?
c. NO: ¿Por qué?

5. ¿Ha ordenado alguna vez prohibir al agresor esconder o trasladar a los niños?

b. NO: ¿Por qué?

6. ¿Ha ordenado al agresor acudir a algún tratamiento reeducativo y terapéutico?
a. Sí: ¿Con qué hechos decide ordenar esto?
b. ¿En esta Comisaría se ofrece el servicio?
c. ¿Sólo lo decreta cuando las partes quie- ren ese tratamiento o incluso lo hace en contra de su voluntad?

d. NO: ¿Por qué?

7. ¿Ha ordenado al agresor alguna vez el pago de los gastos de orientación y asesoría médica y jurídico-psicológica que la víctima requiera? 
a. Sí: ¿Con qué hechos decide ordenar esto?

b. ¿lmporta en algo la capacidad económica del citante y el citado para que Ud. decida aplicar esta medida?

c. NO: ¿Por qué?

8. ¿Alguna vez ha ordenado una protección temporal especial a la víctima por parte de las autoridades de policía?
a. Sí: ¿Cómo se determina la gravedad del maltrato para aplicar esa protección especial?
b. ¿Cómo funciona exactamente?
c. NO: ¿Por qué?

9. ¿Alguna vez ha ordenado a la autoridad de la policía que acompañe a la víctima a su domicilio cuando ésta ha salido para proteger su seguridad?
a. Sî́: ¿Con qué hechos decide hacer esto?
b. Sólo lo hace si la víctima lo pide, o ¿Ud. lo puede hacer oficiosamente?

c. NO: ¿Por qué?

10. ¿Alguna vez ha decidido suspender la tenencia, porte o uso de armas por parte del agresor?

a. Sí: ¿Con qué hechos decidió hacer eso? b. En caso de que sean indispensables para el ejercicio de la profesión del agresor ¿Qué ha decidido?

c. NO: ¿Por qué?

11. Para la decisión provisional del régimen de visitas ¿tiene algo que ver quien haya sido el agresor y si lo fue contra sus hijos?

12. Para la decisión provisional de quién es el que queda encargado de las pensiones alimentarias, ¿tiene algo que ver quién sea el agresor? ¿Por qué?

13. Para la decisión provisional de quién es el que queda con el uso y disfrute de la vivienda familiar, ¿tiene algo que ver quién sea el agresor? ¿Por qué?

14. ¿Alguna vez ha decidido prohibir la realización de cualquier acto de enajenación o gravamen de bienes del agresor para proteger la sociedad conyugal?

15. ¿Alguna vez ha tenido que ordenar la devolución de documentos u objetos personales de la víctima que tenga en su posesión el agresor?
a. ¿Con qué hechos decidió ordenar eso?

\section{Comisarios}

1. ¿Usted siente que su carga de trabajo está bien remunerada?
a. ¿Qué piensa acerca de las condiciones laborales en que usted se desenvuelve, 
cree que esto se pueda ver reflejado en la atención que usted presta?

2. ¿Cómo siente que es el trabajo en coordinación con otras entidades del Estado como instituciones de salud, la policía, los jueces?

3. ¿Hay alguna medida de protección que haya querido implementar y no haya sido posible por falta de recursos económicos y de personal interdisciplinario?

4. ¿Cuándo considera que la aplicación de una medida de protección ha sido efectiva?

Considera que es efectiva: (a pesar de ser una encuesta, la pregunta anterior es abierta y se formula primero para no inducir al entrevistado)

a. Si se da disminución de la violencia.

b. Si desaparece la violencia.

c. Cuando no hay reincidencia en el acto violento.

d. Cuando se hace estrictamente lo que la medida dicte.

5. ¿Cree usted que la intervención estatal es efectiva?

6. ¿Cuándo decide hacer una denuncia penal?
7. Para Suba: ¿Hace cuánto tiempo se implementó el modelo de intervención de terapia familiar? ¿Cómo se estructuró el modelo?, ¿con qué asesoría? ¿En qué consiste? ¿Ya ha sido implementado en algún caso?

8. Para el resto: ¿Se han implementado algunos tipos de medidas diferentes de las que están establecidas en la ley? ¿Cuáles?

9. ¿Qué efecto cree que ha tenido la existencia de las Comisarías en la manera en que las mujeres perciben y se enfrentan al problema de la violencia intrafamiliar?

10. Propuesta de investigación futura: ¿Usted cree que al interior de la familia se cumplen las medidas de prevención tal como fueron decretadas? ¿De qué manera afecta esto las medidas decretadas (sabiendo que las van a modificar)?

11. ¿Con qué frecuencia usa la potestad de hacer "lo que crea pertinente"?
a. Nunca: ¿Por qué?

b. Algunas veces: ¿Por temor a sanción disciplinaria? o ¿se la han iniciado alguna vez?

12. ¿Existen rutas de atención diferenciadas según la gravedad?

a. ¿Cuáles son? ¿Usan rutas diferenciadas según la gravedad del caso? 


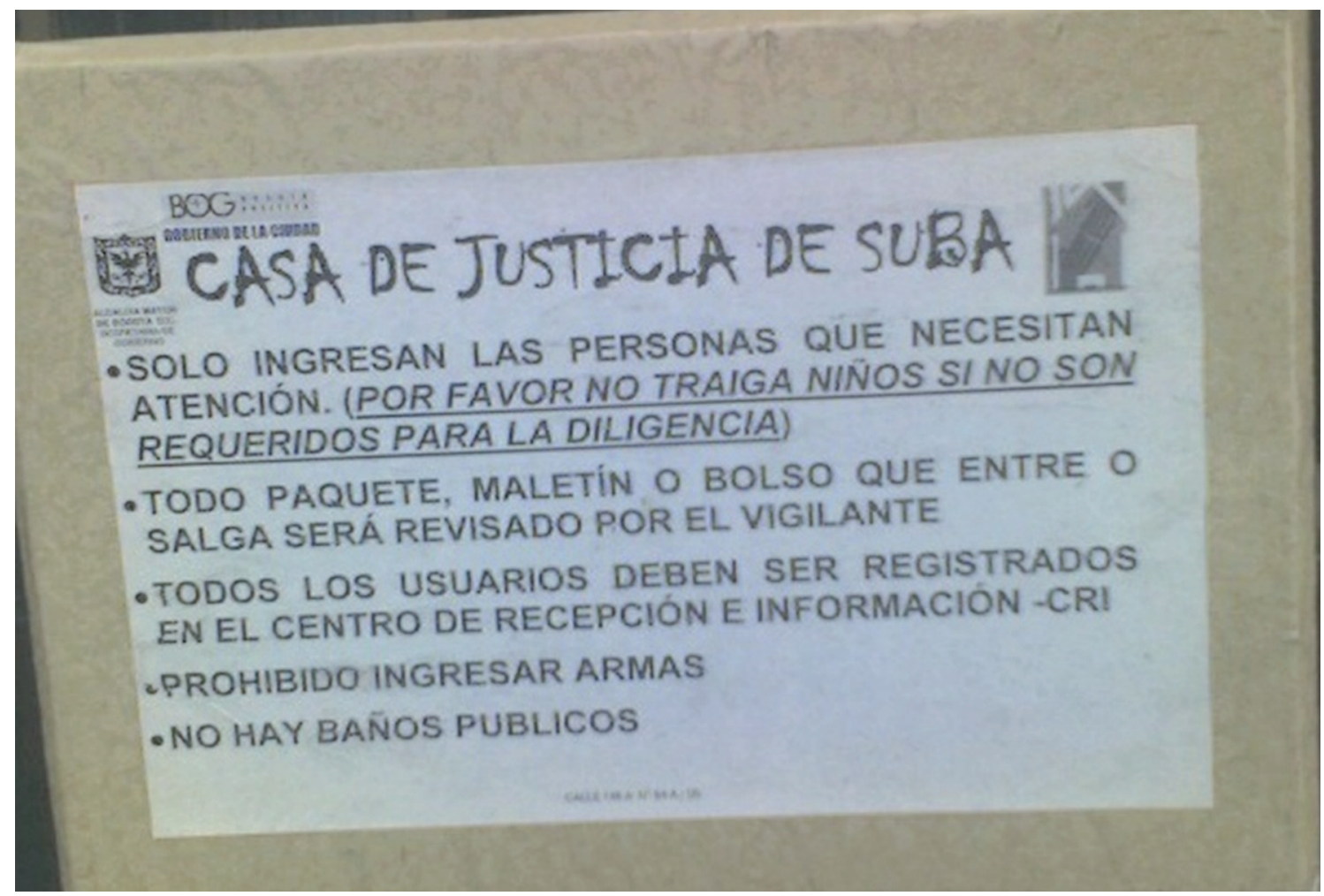

ANEXO 3

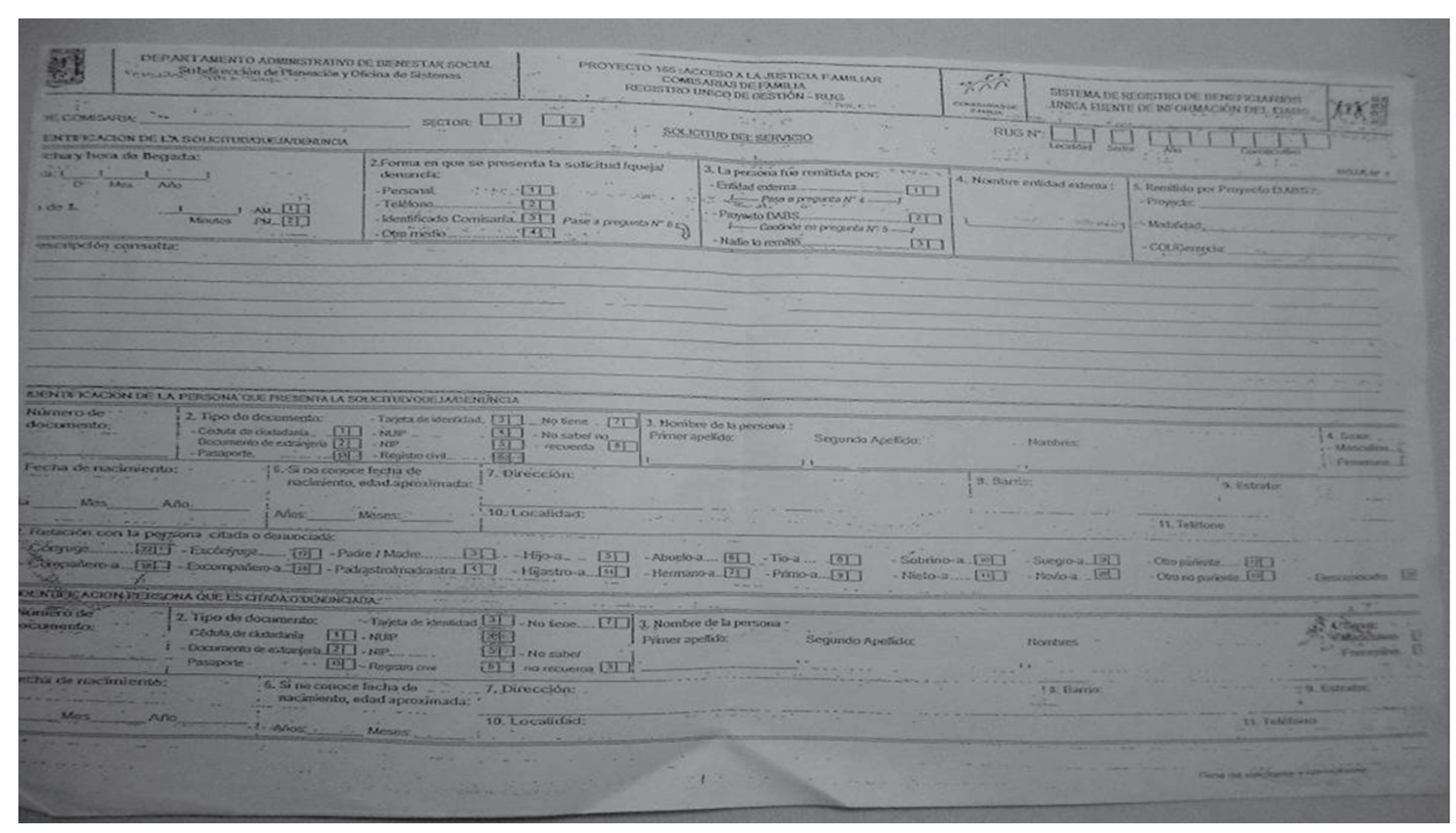

